\title{
Fuzzy-AHP Application in Analyzing the Factors Affecting Quality of Rural Labor
}

\author{
Lich Khac HOANG ${ }^{1}$, Kien The NGUYEN ${ }^{2}$
}

Received: June 03, 2020 Revised: June 28, 2020 Accepted: July 09, 2020

\begin{abstract}
This paper aims to investigate the factors affecting the quality of rural labor in Vietnam, a case study in Thai Nguyen province. For this purpose, we establish an integrated framework of factors affecting the quality of rural labor. We use Fuzzy analytic hierarchy process (FuzzyAHP) to assess the weight of the criteria and sub-criteria of rural labor quality. This method introduced by Saaty (1987) is a useful tool to cope with the complexity of decision-making. The Fuzzy-AHP is one of the most common Multi-Criteria Decision-Making instruments for dealing with quantifiable and intangible criteria, which reflect the relative importance of the alternatives based on constructing a pairwise comparison matrix. The results show that the four most weighted factors are institutions, local government policies, technical qualifications, and mentality. In particular, the weight of the institution is the largest (0.2343), meaning that this factor is the most important one affecting the quality of rural labor in Thai Nguyen province. The weight of local government policy is close to that of institution, about 0.2259 . The weights of technical qualification and mentality are 0.1238 and 0.1135 , respectively. In addition, age and education levels do not significantly affect the rural labor quality of Thai Nguyen province.
\end{abstract}

Keywords: Labor Quality, Countryside, Fuzzy AHP

JEL Classification Code: R23, O15, O18, J24, J43

\section{Introduction}

High-quality labor is a crucial element in almost every economy that is based on the interrelated factors of human capital and long-term economic growth (Van Tran, Alauddin, \& Van Tran, 2019). The reality of domestic and foreign economic development proves that the aggregate quality of rural labor is not only related to the efficiency and development of agricultural potential, but is also a very important factor for the socio-economic development of countries. Vietnam has been industrializing and modernizing rural areas for quite a long time, but the stability of agricultural

${ }^{1}$ First Author and Corresponding Author. VNU University of Economics and Business, Hanoi, Vietnam [Postal Address: 144 Xuan Thuy Street, Cau Giay District, Hanoi, 100000, Vietnam] Email: hoangkhaclich@gmail.com ; lichhk@vnu.edu.vn

2VNU University of Economics and Business, Hanoi 100000, Vietnam. Email: thekien.edu@gmail.com

(C) Copyright: The Author(s)

This is an Open Access article distributed under the terms of the Creative Commons Attribution Non-Commercial License (http://Creativecommons.org/licenses/by-nc/4.0/) which permits unrestricted noncommercial use, distribution, and reproduction in any medium, provided the original work is properly cited. production, in particular, and the rural economy, in general, are still faced with serious market challenges. Vietnam, in general, and the Thai Nguyen province, in particular, has a large rural labor force, but human resources are very limited in terms of quality.

There is a vast body of literature measuring labor quality, such as Jorgenson and Grilliches (1967), Ho and Jorgenson (1999), Jorgenson and Stiroh (2000), Fosgerau, Hougaard Jensen and Sørensen (2002) and Haerani, Sumardi, Hakim, Hartini, and Putra (2020). Many studies employ the method of Gollop, Fraumeni and Jorgenson (1987) and use the Tornqvist translog index. However, these methods are no longer commonly used. To assess the quality of human resources, studies in Vietnam often use traditional methods such as descriptive statistical analysis, regression analysis, and a number of recent studies using the Cronbach's Alpha reliability to assess the reliability of the scale. For example, Le, Duy and Ngoc (2019) investigate whether foreign direct investment (FDI) has positive effect on the labor productivity in Vietnam. The authors use Autoregressive Distributed Lag (ARDL) model to examine the effect of FDI and human capital on labor productivity in Vietnam from 1986 to 2014. Many other researchers use multiple regression analysis and 
EFA discovery factor analysis model (e.g., Cam, 2013; Duc, 2012; Vu, 2015; Cong, 2016; Tien, 2016; Duy, 2018; among others).

Currently, fuzzy analysis is widely applied in economics and management to determine the weight of factors and then choose the best solution to solve the problem. For example, Farajnejad and Lau (2017) employ a fuzzy logic method to construct the early-warning system of banking crisis based on 21 pre-determined variables from the aspect of total economy, financial and banking sectors. However, it is difficult to find a study utilizing fuzzy methods to analyze the factors affecting the quality of rural labor, especially for the quality of rural labor in Vietnam. In this paper, we use the Fuzzy AHP model to calculate the influence of factors on the quality of rural labor in Vietnam. We believe that the appropriate approach and empirical findings from this article will not only enrich the Fuzzy AHP model application literature, but also generate effective recommendations for policymakers on rural labor quality improvement strategy.

Thai Nguyen province was chosen to represent the study of rural labor quality. In particular, rural workers in Thai Nguyen province is the case study. Thai Nguyen is a mountainous midland province in northeastern Vietnam, one of the provinces with the highest percentage of agricultural labor in the country. The paper aims to build a theoretical framework for factors affecting rural labor quality, from which the application of Fuzzy AHP model assesses the impact level of factors based on the evaluation level of three experts and the average rating of 30 rural workers' representatives surveyed.

The rest of the paper is organized as follows. Section 2 presents the study area, criteria determination, and Fuzzy AHP. Section 3 presents the content of determining the comparative relationship between pairs of factors, calculating the possible level of comparison between two fuzzy numbers, and calculating the weight of factors. The conclusion is discussed in the last section.

\section{Research Methodology}

\subsection{Study Area}

Thai Nguyen Province, being the political and economic center of the midland and mountainous areas of northeastern Vietnam, is the gateway of socio-economic exchanges between the mountainous midland and the northern plain; the North borders Bac Kan province, the West borders with Vinh Phuc and Tuyen Quang provinces, the East borders with the provinces of Lang Son, Bac Giang and the South borders with Hanoi capital ( $80 \mathrm{~km}$ away); it is natural area of $3,562.82 \mathrm{~km}^{2}$.

In 2018, the labor force aged 15 and above in the province reached 774,100 people, an increase of 5,200 people compared to 2017. The labor force aged 15 and over working in economic sectors in 2018 reached 765,700 people, out of which the majority of workers were involved in agriculture, forestry and fisheries, accounting for $40.67 \%$; industry and construction, accounting for $32.12 \%$; and service sector, accounting for $27.2 \%$. The unemployment rate of the labor force in 2018 was $1.19 \%-1.49 \%$ for urban areas and $1.05 \%$ for rural areas. The underemployment rate of the labor force in working age in 2018 was $1.35 \%-0.76 \%$ for the urban area and $1.62 \%$ for the rural area. Compared to 2017, the unemployment rate of the labor force in the working age group in 2018 was 0.49 percentage points lower, but the underemployment rate was 0.88 percentage points higher, in which the rural area was 1.04 percentage points higher. The number of trained local workers is small. Currently, only $21.5 \%$ of workers in the labor force are trained (trained workers are those who have studied and graduated from elementary or higher level). In urban areas, the number of trained workers is $45.3 \%$, in rural areas only $13.5 \%$ (see Thai Nguyen's annual statistics report, 2018).

Employment for workers is always one of the top concerns of local authorities, deciding on the welfare of rural areas. Nevertheless, in the past five years, the rate of unemployed workers tended to increase, unstably, with an average annual increase of about 2000 people in the working age group, equivalent to about $0.37 \%$ of the labor force in rural areas. Although this figure is lower than the general level of the whole country, there is still much potential to increase in the future. Regarding the living standards of the people in general, comparing with the average level of the whole country, the income of rural workers is largely dependent on wages, accounting for $62 \%$ - only about $23 \%$ of income from farming activities, forestry and fisheries. Income from non-agricultural activities has been increasing over the years, which is consistent with the reduction of agricultural labor structure, shift to rural modernization, rapid increase in industrial value, and regional service according to the orientation and rule of market economy development. In view of the above-mentioned labor situation, the fact is that to successfully implement the new rural construction program and the industrialization and modernization of rural agriculture and improve the quality of life of rural people, improving the quality of rural labor is one of the top priorities that require various levels of government to address.

\subsection{Defining the Criteria}

In recent years, a number of domestic or foreign authors have conducted research on labor quality and rural labor quality. The authors suggested the following groups of criteria and sub-criteria to conduct labor quality assessment.

Janeska and Bojnec (2011) pointed out that the rural and agricultural labor market in Macedonia encountered an 
inadequacy for the age benefit, education level and spatial distribution of total employment. At the same time, the authors argued that the demographic recovery in rural areas depends on economic recovery, with a more rational use of labor force and human resources, as well as restructuring agricultural production and agricultural areas. Bai (2012) pointed out the group of criteria for assessing demographic quality. It includes 12 criteria divided into three groups of criteria: group of criteria for evaluating self-quality; group of criteria for evaluating cultural quality; group of criteria to assess the quality of labor skills. Duan and Duan (2011) pointed out 13 criteria, divided into three groups of criteria affecting the quality of human resources, including: group of external conditions criteria on population quality; group of internal subjective criteria of population quality; and group of population and economic structure criteria (see Figure 1).

As regards typical domestic studies, Thuy (2012) focused on researching education and training elements; natural and biological characteristics; health and medical care; social policies; ethnic traditions and culture; family factors; and arranging and employing mountain woman labor resources. Duc (2012) used the indicators of human resource quality as the group of criteria to assess the quality of human resources according to the potential labor capacity, including criteria to assess universal education level information, technical qualifications, cumulative experience, health status, etc.; the second group is the criteria to assess the quality of human resources according to existing competencies including knowledge, job skills, behavior, discipline, level of commitment, cognitive ability, and level of job completion. Cong (2016) studied the factors affecting the quality of human resources such as the group of factors belonging to the state, including elements of local government, and factors of central government; the second group of factors belonging to the local socio-economic environment including factors such as economy, culture, etc.; the third group of science and technology elements; the fourth group of elements of natural conditions; the fifth is a group of factors belonging to employees including qualifications, attitudes, and physical conditions.

Through an overview of domestic and international studies, based on the inheritance and development of previous studies, and interviews with experts, combined with understanding and research, the author proposes a number of factors affecting the quality of rural labor, as shown in Figure 1.

\subsection{Fuzzy AHP}

Fuzzy set theory can solve the uncertain information and vagueness of human' thinking (Braendle, Sepasi \& Rahdari, 2014; Syed, Beg \& Khalid, 2016; Brotons \& Sansalvador, 2017). One popular application of fuzzy set theory, the Analytic Hierarchy Process (AHP) method introduced by Saaty (1987), is a useful tool to cope with the complexity of decision-making. The AHP is one of the most common Multi-Criteria Decision-Making instruments to deal with quantifiable and intangible criteria, which reflect the

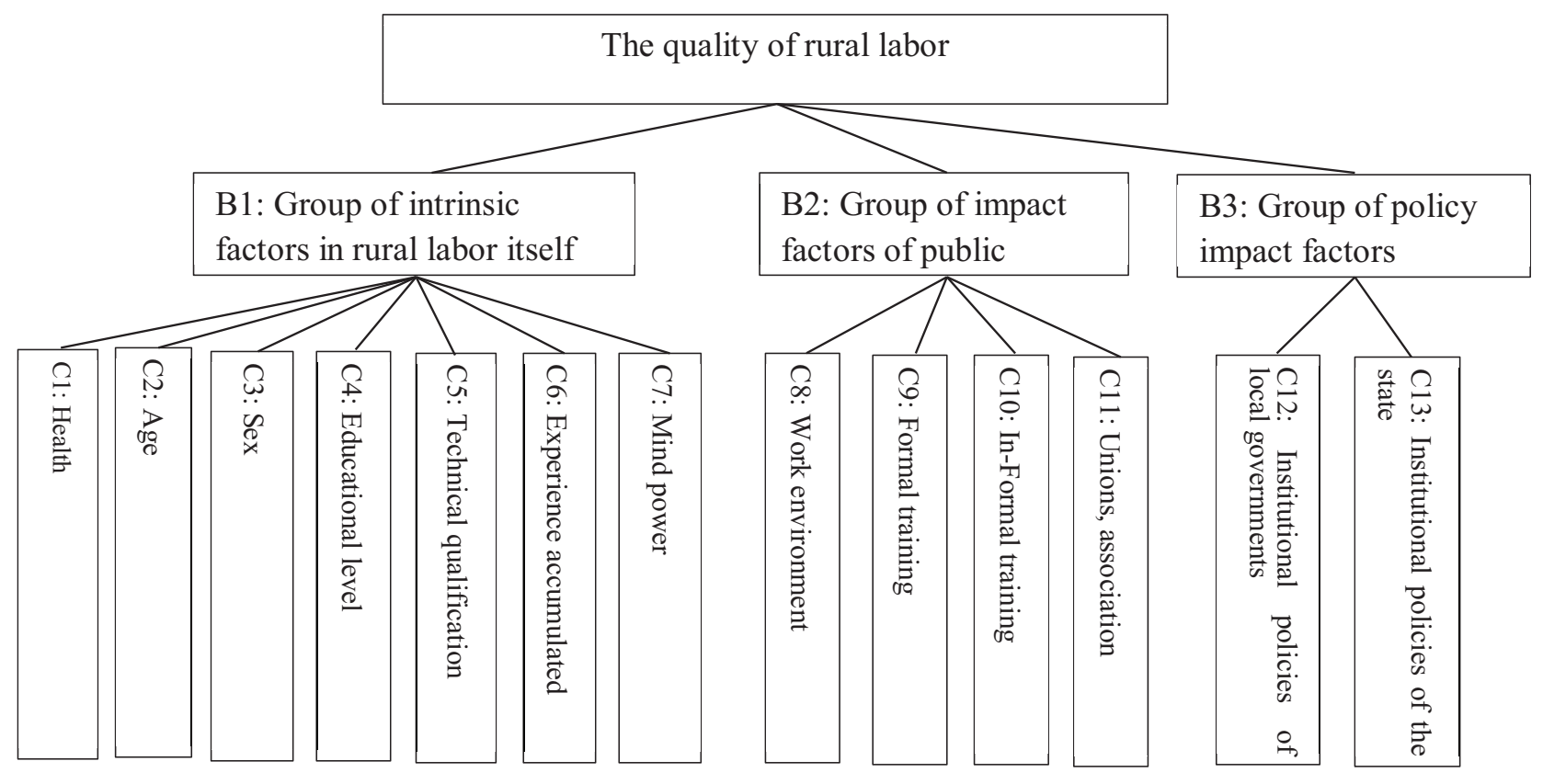

Figure 1: Factors affecting the quality of rural labor 
relative importance of the alternatives based on constructing a pairwise comparison matrix (Vargas, 1990; Carnero, 2014; and Chang, 1996). Fuzzy AHP was developed to determine the weights of multiple criteria (Pourjavad \& Mayorga, 2016). While the traditional AHP faces limitations on information imprecision and vagueness for decisionmaking, the fuzzy AHP solves these problems of imprecision using linguistic variables, which are used to represent the relative importance between each pair of criteria (Van Tran, Alauddin, \& Van Tran, 2019).

The hierarchical analysis model is implemented as follows:

Firstly, we analyze a hierarchical structure to grasp the basic content of the problem, such as comparing the factors affecting the quality of rural labor, divided into group factors and factor themselves. Influencing factors are presented as a hierarchical structure for comparing the weight of factors (details are shown in Table 1).

Secondly, the assessment council compares the level of importance of factor groups and factors themselves; then determining the most important factors affecting the quality of rural labor in Thai Nguyen province, based on fuzzy set of scales including linguistic criteria.

After comparing factors, the fuzzy AHP hierarchical model is used to determine the weight of the factors affecting the quality of rural labor in Thai Nguyen province.

Thirdly, we perform AHP hierarchical fuzzy analysis. This model uses linguistic variables to represent comparative assessments. The fuzzy matrix looks like this:

$$
\begin{aligned}
M & =\left(M_{i j}\right)_{n \times n} \\
& =\left[\begin{array}{cccc}
(1,1,1) & \left(l_{12}, m_{12}, u_{12}\right) & \ldots & \left(l_{1 n}, m_{1 n}, u_{1 n}\right) \\
\left(l_{21}, m_{21}, u_{21}\right) & (1,1,1) & \ldots & \left(l_{2 n}, m_{2 n}, u_{2 n}\right) \\
\vdots & \vdots & \vdots & \vdots \\
\left(l_{n 1}, m_{n 1}, u_{n 1}\right) & \left(l_{n 2}, m_{n 2}, u_{n 2}\right) & \ldots & (1,1,1)
\end{array}\right]
\end{aligned}
$$

Table 1: Assessment scale of the pairwise comparison relationship

\begin{tabular}{|l|c|c|}
\hline \multicolumn{1}{|c|}{ Language criteria } & $\begin{array}{c}\text { Fuzzy } \\
\text { numbers }\end{array}$ & $\begin{array}{c}\text { Inverse triangular } \\
\text { fuzzy numbers }\end{array}$ \\
\hline Equally important (EI) & $(1,1,1)$ & $(1,1,1)$ \\
\hline Less important (MI) & $(1,3,5)$ & $(1 / 5,1 / 3,1)$ \\
\hline $\begin{array}{l}\text { Relatively important } \\
\text { (SI) }\end{array}$ & $(3,5,7)$ & $(1 / 7,1 / 5,1 / 3)$ \\
\hline Very important (VSI) & $(5,7,9)$ & $(1 / 9,1 / 7,1 / 5)$ \\
\hline $\begin{array}{l}\text { Extremely important } \\
\text { (EXI) }\end{array}$ & $(7,9,9)$ & $(1 / 9,1 / 9,1 / 7)$ \\
\hline
\end{tabular}

where

$$
\begin{aligned}
& M_{i j}=\left(l_{i j}, m_{i j}, u_{i j}\right) \text { và } M_{i j}^{-1}=\left(1 / u_{i j}, 1 / m_{i j}, 1 / l_{i j}\right) \\
& \text { với } i, j=1, \ldots, n \text { và } i \neq \mathrm{j} .
\end{aligned}
$$

According to Chang (1996), the steps of a broad fuzzy analysis can be described briefly as follows:

Step 1: Calculate the aggregated fuzzy number for the $\mathrm{i}^{\text {th }}$ object by the formula:

$$
\begin{aligned}
S_{i} & =\sum_{j=1}^{m} M_{i j} \otimes\left[\sum_{k=1}^{n} \sum_{j=1}^{n} M_{k j}\right]^{-1} \\
& =\left(\frac{\sum_{j=1}^{n} l_{i j}}{\sum_{k=1}^{n} \sum_{j=1}^{n} u_{k j}}, \frac{\sum_{j=1}^{n} m_{i j}}{\sum_{k=1}^{n} \sum_{j=1}^{n} m_{k j}}, \frac{\sum_{j=1}^{n} u_{i j}}{\sum_{k=1}^{n} \sum_{j=1}^{n} l_{k j}}\right)
\end{aligned}
$$

with $\mathrm{i}=1, \ldots, n$.

In which $\otimes$ denotes the multiplication of two fuzzy numbers (section 3.2).

Step 2: Calculate the possible degree of the comparison relationship between every two fuzzy numbers:

$$
V\left(S_{i} \geq S_{j}\right)=\sup _{y \geq x}\left[\min \left(S_{j}(x), S_{i}(y)\right)\right]
$$

The above formula can be expressed as follows:

$$
\begin{aligned}
& V\left(S_{i} \geq S_{j}\right) \\
& \quad=\left\{\begin{array}{c}
1, m_{i} \geq m_{j} \\
\frac{u_{i}-l_{j}}{\left(u_{i}-m_{i}\right)+\left(m_{j}-l_{j}\right)}, l_{j} \leq u_{i} \quad i, j=1, \ldots, n ; i \neq j \\
0, \text { otherwise }
\end{array}\right.
\end{aligned}
$$

where

$$
S_{i}=\left(l_{i}, m_{i}, u_{i}\right) \text { và } S_{j}=\left(l_{j}, m_{j}, u_{j}\right) .
$$

Step 3: Calculate the possible level of the likelihood of some fuzzy relationships:

$$
\begin{aligned}
V(\mathrm{~S} & \left.\geq S_{1}, S_{2}, \ldots \mathrm{S}_{n}\right) \\
\quad & =V\left[\left(S \geq S_{1}\right) \text { and }\left(\mathrm{S} \geq \mathrm{S}_{2}\right) \ldots \text { and }\left(S \geq S_{n}\right)\right] \\
& =\min V\left(S \geq S_{i}\right)
\end{aligned}
$$

with $\mathrm{i}=1,2, \ldots, \mathrm{n}$.

Step 4: Calculate the vector W':

$$
\mathrm{W}^{\prime}=\left(d^{\prime}\left(A_{1}\right), d^{\prime}\left(A_{2}\right), \ldots, d^{\prime}\left(A_{n}\right)\right)^{T}
$$


with the assumption that: $d^{\prime}\left(A_{i}\right)=\min V\left(S_{i} \geq S_{t}\right)$ and $i=$ $1,2, \ldots, \mathrm{n} ; \mathrm{t}=1,2, \ldots . \mathrm{n}$ and $\mathrm{i} \neq \mathrm{t}$.

The normalized weight vectors $\mathrm{W}^{\prime}$ is generated according to the pairwise comparisons between criteria. As far as the important the corresponding criterion is concerned, the higher the weight, the more important the corresponding criterion.

Fourthly, we conduct the factor ranking analysis. The results determine which factors have the highest weight, accounting for the most important role in the factors affecting the quality of rural labor in Thai Nguyen province.

\section{Research Results}

After determining the criteria for assessing the factors affecting the quality of rural labor in Thai Nguyen province, the council members were asked to make factor-pairwise comparison. The average evaluation of the factor-pairwise relationship is calculated by the average of the four board members' results using formulas (1). Taking these results into account, we then use equation (2) - (4) to calculate the possible degree of the comparison relationship between every two fuzzy numbers. Next, using the formulas (5), we get the weight of the factors as follows (see Table 2).

Table 2 shows that, the content of the intrinsic factor group of rural workers themselves has the highest weight of 0.5 , thereby giving the role of this factor group is the most important in the quality of rural labor.

The four most weighted criteria include institutional policies of the state, policies of local governments, technical qualifications, and mentality. In particular, the weight of the C13 criterion is the largest $(0.2343)$, corresponding to the most important $\mathrm{C} 13$ criterion among the factors affecting the quality of rural labor in Thai Nguyen province. This corresponds to reality because the state institutional policy represents the government through direct support channels for improving the quality of rural human resources. Investment in education and health is especially one of the important factors affecting the development of rural human resources. In fact, in Thai Nguyen province, agricultural human resources mainly live in mountainous, remote areas that lack physical facilities, transport infrastructure. Some places in Thai Nguyen still have backward habits and customs, underdeveloped education and health; and, farmers are considered to be one of the vulnerable groups. Thus, the government must strengthen policies to invest in this area.

Followed by ranking 2 is the policy of the local government $(0.2259)$, which demonstrates the vital role of local governments in planning and implementing appropriate policies in each locality, which contributes significantly to improve the quality of rural labor.

The third is the weight of the criteria of technical and professional qualifications (0.1238), Criteria for professional and technical qualifications, especially vocational education, are factors that significantly affect the quality of rural labor. The rural labor force in Thai Nguyen is mainly poorly educated; indeed, most of the workers have not been trained; their ability to adapt to the development of high-tech agriculture is still deficient. Therefore, improving the quality of rural labor, effectively using rural human resources, and

Table 2: The weight of the factors

\begin{tabular}{|c|c|c|c|c|c|c|}
\hline Target class & Weight (A) & Content class & Weight (B) & Criteria & Weight (C) & Rank \\
\hline \multirow{13}{*}{$\begin{array}{l}\text { Factors } \\
\text { affecting the } \\
\text { quality of } \\
\text { rural labor in } \\
\text { Thai Nguyen } \\
\text { province (A) }\end{array}$} & \multirow{13}{*}{1} & \multirow{7}{*}{$\begin{array}{c}\text { Group of } \\
\text { intrinsic } \\
\text { factors in rural } \\
\text { labor itself } \\
\text { (B1) }\end{array}$} & \multirow{7}{*}{0.50} & Health (C1) & 0.0770 & 6 \\
\hline & & & & Age (C2) & 0.0000 & 13 \\
\hline & & & & Sex (C3) & 0.0763 & 7 \\
\hline & & & & Educational level (C4) & 0.0000 & 12 \\
\hline & & & & Technical qualification (C5) & 0.1238 & 3 \\
\hline & & & & Experience accumulated (C6) & 0.1127 & 5 \\
\hline & & & & Mind power $(\mathrm{C} 7)$ & 0.1135 & 4 \\
\hline & & \multirow{4}{*}{$\begin{array}{c}\text { Group of } \\
\text { factors } \\
\text { affecting public } \\
\text { investment } \\
\text { (B2) }\end{array}$} & \multirow{4}{*}{0.04} & Working environment (C8) & 0.0062 & 10 \\
\hline & & & & Formal training (C9) & 0.0126 & 9 \\
\hline & & & & Non-mainstream training (C10) & 0.0141 & 8 \\
\hline & & & & Unions and societies (C11) & 0.0038 & 11 \\
\hline & & \multirow{2}{*}{$\begin{array}{c}\text { Group of } \\
\text { policy impact } \\
\text { factors (B3) }\end{array}$} & \multirow[t]{2}{*}{0.46} & $\begin{array}{l}\text { Institutional policies of local } \\
\text { governments (C12) }\end{array}$ & 0.2259 & 2 \\
\hline & & & & State institutional policy (C13) & 0.2343 & 1 \\
\hline
\end{tabular}


improving the rural vocational education system are urgent tasks. Criteria $\mathrm{C} 4$ is assessed as not really important to determine the superiority of the factors affecting the quality of rural labor in Thai Nguyen province. In fact, universalizing education and eradicating illiteracy have been major concerns of the government recently. Thus, human resources' intellectual standard will be improved to adapt to the industrialization and modernization of the country. In recent years, Thai Nguyen province has actively implemented the universalization of education in the region and has achieved remarkable results. This is one of the reasons that the level of education is not marked as outstanding. The research results form the basis for conclusions and recommendations.

\section{Conclusions}

To develop the rural economy, it is necessary to develop human factors in this area. Developing rural agriculture economy towards modernization is the urgent requirement, which demands people to quickly adapt and respond to those changes. Thus, a premise for comprehensive and sustainable rural agriculture development is created. Thai Nguyen is a very diverse province in terms of production and business activities. Thai Nguyen has specific characteristics of rural areas and rural labor spread throughout the area and is divided into three distinct areas - highland, delta, and metropolitan area. The rural labor force accounts for over $70 \%$ of the provincial labor force and is on a decreasing trend; therefore, it is mandatory to increase the quality of rural labor. Moreover, improving the quality of rural labor, enhancing social security in rural areas to meet standards swiftly, and increasing agricultural productivity industry toward high technology are issues the local authorities as well as the government have been paid great attention.

Based on an overview of ethics and practice, the paper used a decentralization process to establish a hierarchical structure of factors affecting the quality of rural labor in Thai Nguyen province, including three factor groups containing 13 factors. Then, we apply Fuzzy AHP hierarchical analysis model to determine the weight of each factor affecting the quality of rural labor resources.

Specifically, endogenous factors of rural labor force include health $(\mathrm{C} 1)$, age $(\mathrm{C} 2)$, gender $(\mathrm{C} 3)$, education level (C4), technical and professional level (C5), accumulated experience (C6), mindfulness (C7), which are the most important ones. Assessing the status of rural labor quality in Thai Nguyen province through groups of endogenous factors of rural workers such as health, knowledge, skills, attitudes, etc., in general, ensuring the basic requirements of their non-intensive work and current intensive jobs. Health of workers is generally good, ensuring they are performing the work; the age and gender of these workers is quite young, the percentage of elderly laborers is lower than the general level of the whole country and the world; the gender ratio in labor is not much different. Basic education levels have been universalized, only a very few of them have not been trained, most of them are elderly labors; the technical and professional qualifications are above average, most of them are trained at apprenticeship, about one third of the workers are properly and officially trained. The evaluation of the survey sample also shows that this group of workers has relatively good knowledge and skills, sufficient to meet the jobs requirement in rural areas.

The second most weighted group is the group of policy impact factors on rural labor, including institutional policies of local governments $(\mathrm{C} 12)$ and institutional policies of the state (C13). This is one of the factors that have a decisive role in the labor efficiency of rural activities. Survey of attitude factors also shows that macroeconomic policy for economic development in rural areas is very important, it directly affects the working needs and willingness of workers. The requirement for impact of market mechanism is the priority, because workers are afraid of risk as they have been exposed to many risks in their production activities. Moreover, due to the lack of information and orientation of the state for production activities, the apprehension and proactiveness hinder the capacity of rural labor. Regarding the policies of local governments, the close attention of the management agencies has a great impact on the performance of each household and employee in the local area, something the government's policy is unable to directly access; the clearer the local policies are, the more effective the labor activity is. In the past five years, the rural economy in Thai Nguyen province has improved significantly. Labor productivity has increased, but it is still much lower than that of the region and the world. It is necessary to have many urgent and coordinated solutions to overcome this problem.

The third weighted group is the group of impact factors of public investment, including working environment (C8), formal training (C9), informal training (C10), and unions, associations (C11). The influencing factors have shown that through the impact assessment of public investment factors group, the rural labor environment only meets $50 \%$ of labor demand in the rural areas, there are still many laborers unhappy about the local environment. Formal training is evaluated to be much better than demand-driven training, with a large number of workers claiming that on-demand training is only supportive for the current job, not when the job is changing. Unions and associations' activities are mostly attended by this force, but its effectiveness is not high; it mainly helps workers find opportunities to change their work structure or access capital from organizations.

Therefore, the achievements of the application of the AHP model in the assessment of rural labor quality in Thai Nguyen province shows that, in order to improve the quality of village labor, managers and policymakers should use the 
priority in weighting the factor groups. At the same time, the most optimal policies to improve the quality of rural labor are proposed base on the actual situation and potential of the method.

In addition to the obtained results, the authors acknowledge some limitations of the study, such as the research has not calculated the weight of the council members. Moreover, the impact of factors on the quality of rural labor has only been analyzed without measuring the actual quality of the rural workforce in Thai Nguyen province. These are also implications for future research, which is necessary for Vietnam rural areas nowadays.

\section{References}

Bai, C. J. (2012). An empirical analysis of the relationship between the country's population quality and economic development. Market Modernization, 681, 93-95.

Braendle, U., Sepasi, S., \& Rahdari, A. H. (2014). Fuzzy evaluation of service quality in the banking sector: A decision support system. Fuzzy Economic Review, 19(2), 47-79.

Brotons, J. M., \& Sansalvador, M. E. (2017). A fuzzy model for the quantification of cost of quality based on the aggregation of information. Fuzzy Economic Review, 22(1). DOI: 10.25102/ fer.2017.01.03

Cam, N. T. H. (2013). Improving the quality of human resources in Vietnam's wood processing industry enterprises. Doctoral Dissertation, Vietnam National University of Economics, Vietnam.

Carnero, M. C. (2014). Multicriteria model for maintenance benchmarking. Journal of Manufacturing Systems, 33(2), 303321.

Chang, D. Y. (1996). Applications of the extent analysis method on fuzzy AHP. European Journal of Operational Research, 95(3), 649-655.

Duan, L. G., \& Duan, L. L. (2011). Research on the Quality of Population Based on AHP. Mathematics in Practice and Theory, 41, 246-256

Duc, N. B. (2012). Quality of human resources in industrial zones in Danang City. Doctoral Dissertation, Ho Chi Minh National Academy of Politics and Public Administration, Vietnam.

Duy, T. L. (2018). Improving the quality of rural human resources in Thai Nguyen province. Doctoral Dissertation, TNU-University of Economics and Business Administration, Vietnam.

Farajnejad, E., \& Lau, W. Y. (2017). A Fuzzy Based Early Warning System to Predict Banking Distress on Selected AsiaPacific Countries. Journal of Asian Finance, Economics and Business, 4(1), 39-49. http://dx.doi.org/10.13106/jafeb.2017. vol4.no1.39

Fosgerau, M., Hougaard Jensen, S. E., \& Sørensen, A. (2002). Measuring Educational Heterogeneity and Labor Quality: A Note. Review of Income and Wealth, 48(2), 261-269.

Gollop, F. M., Fraumeni, B. M., \& Jorgenson, D. W. (1987). Productivity and US economic growth. Amsterdam, Netherlands: North Holland.
Haerani, S., Sumardi, S., Hakim, W., Hartini, H., \& Putra, A. H. P. K. (2020). Structural Model of Developing Human Resources Performance: Empirical Study of Indonesia States Owned Enterprises. Journal of Asian Finance, Economics, and Business, 7(3), 211-221. https://doi.org/10.13106/jafeb.2020. vol7.no3.211

Ho, M. S., \& Jorgenson, D. W. (1999). The quality of the US Workforce, 1948-95. Harvard University.

Janeska, V., \& Bojnec, Š. (2011). Rural Labor Market Developments in the Former Yugoslav Republic of Macedonia. Factor Markets Working Paper No. 5. Brussels, Belgium: Centre for European Policy Studies (CEPS). http://aei.pitt.edu/58507/1/ Factor_Markets_5.pdf

Jorgenson, D. W., \& Griliches, Z. (1967). The explanation of productivity change. The Review of Economic Studies, 34(3), 249-283.

Jorgenson, D. W., \& Stiroh, K. J. (2000). US economic growth at the industry level. American Economic Review, 90(2), 161-167.

Le, N. H., Duy, L. V. Q., \& Ngoc, B. H. (2019). Effects of Foreign Direct Investment and Human Capital on Labour Productivity: Evidence from Vietnam. Journal of Asian Finance, Economics and Business, 6(3), 123-130. https://doi.org/10.13106/ jafeb.2019.vol6.no3.123

Pourjavad, E.H. S.A. N., \& Mayorga, R. V.(2016). A hybrid approach integrating AHP and TOPSIS for sustainable end-of-life vehicle strategy evaluation under fuzzy environment. WSEAS Transactions on Circuits and Systems, 15, 216-223.

Syed, A., Beg, I., \& Khalid, A. (2016). Aggregation methods for fuzzy judgments. Fuzzy Economic Review, 21(1), 3-21.

Saaty, R. W. (1987). The analytic hierarchy process - what it is and how it is used. Mathematical Modelling, 9(3-5), 161-176.

Tien, P.D. (2016). Developing high-quality human resources in the process of international integration. Doctoral Dissertation, Hanoi Vietnam National University, Vietnam.

Thai Nguyen's Annual Statistics Report (2018). General Statistics Office of Viet Nam. Retrieved January 20, 2020 from: https://www.gso.gov.vn/default en. aspx?tabid $=509 \&$ idmid $=1 \&$ itemid $=2731$

Thuy, L. T. (2012). Development of female human resources for economic growth and social justice implementation in the northern mountainous region of Vietnam. Doctoral Dissertation, Central Institute for Economic Management, Vietnam.

Van Tran, N., Alauddin, M., \& Van Tran, Q. (2019). Labor quality and benefits reaped from global economic integration: An application of dynamic panel SGMM estimators. Economic Analysis and Policy, 63, 92-106.

Vargas, L. G. (1990). An overview of the analytic hierarchy process and its applications. European Journal of Operational Research, 48(1), 2-8.

$\mathrm{Vu}$, N.T. (2015). Studying factors affecting human resource development of textile enterprises in Tien Giang province. Doctoral Dissertation, Ho Chi Minh University of Economics, Vietnam. 